\title{
That was then, this is now: skills and routinization in the 2000s
}

\author{
Davide Consoli \\ INGENIO (CSIC-UPV) (Spain) \\ e-mail: davide.consoli@ingenio.upv.es \\ Francesco Vona* \\ OFCE Sciences-Po and SKEMA Business School (France) \\ e-mail: francesco.vona@sciencespo.fr \\ Francesco Rentocchini \\ Southampton Business School (UK) \\ e-mail: f.rentocchini@soton.ac.uk
}

\begin{abstract}
We analyze changes in the skill content of occupations in US four-digit manufacturing industries between 1999 and 2010. Following a 'task-based' approach, we elaborate a measure of non-routine skill intensity that captures the effects of industry exposure to both technology and international trade. The paper adds to previous literature by focusing on both the determinants of demand for non-routine skills and their effects on industry productivity and wages. The key finding is that import competition from low-wage countries has been a strong driver of demand for non-routine skills during the 2000s. Both technology and trade with low-wage countries are associated with mild cross-industry convergence in skill intensity, while trade with high- and medium-wage countries are at the root of persistent heterogeneity across occupational groups. We also find that higher nonroutine skill intensity has had, at best, a modest effect on productivity and wages, except in high-skill occupations.
\end{abstract}

Keywords: Skills, Tasks, Routinization, Trade, Technology.

JEL Classifications: F16, J21, J23, O33

(*) Corresponding author 


\section{Introduction}

This paper elaborates an empirical study of changes in the skill content of occupations in US manufacturing industries from 1999-2010. Our goal is to elaborate an assessment of the key drivers of changes in workforce composition by focusing on non-routine (NR) skills, a particular set of workers' abilities that are used when carrying out analytical and interactive tasks. The relationship between job tasks and skills is a staple of a flourishing strand of research on the relationship between capital and labor. The seminal study by Autor, Levy and Murnane (2003) on the effects that computer technology exerted on the composition of employment in the 1990s found a substitution effect for routine-intensive occupations, such as clerks, and complementarity with managerial, professional and technical occupations. Given the argument that the shock wave of the 1990s may have subsided due to the stabilization of the computer's life-cycle (see e.g., Vona and Consoli, 2015), we take stock of the empirical evidence and gauge the effect of technology on the demand for skills and on occupational composition in the 2000s. Our analysis also takes into account the remarkable growth of international trade due to the expansion of China and other emerging economies (Hanson, 2012). We note that, although a few exceptions (e.g., Lu and Ng, 2013) exist, there are no systematic accounts of how trade has reshaped the skill content of occupations and industries. Filling this gap is the second objective of the paper.

Our analysis yields three main findings. First and foremost, import competition from lowwage countries emerges as a stronger driver of demand for non-routine skills than technology in the 2000s. Second, both technology and imports from low-wage countries are associated with skill convergence across industries. This finding is consistent with the literature showing that trade-induced adjustments are stronger in industries with lower initial skill levels (Bugamelli et al., 2008; Pierce and Schott, 2012). Furthermore, when allowing for heterogeneity across occupational groups, we find that the convergence of NR skill intensity 
across industries is not driven by convergence across occupations. Conversely, heterogeneity across occupational groups is persistent due to imports from high- and medium-wage countries. The last major finding is that upgrading non-routine skills has, at best, a modest effect on productivity and wages, except for in high-skill occupations.

The paper is structured as follows. Section 2 reviews the literature. Section 3 outlines the empirical strategy, and Section 4 describes the dataset. The central part of the paper involves the analysis of the determinants of NR skills; Section 5 presents the baseline model and unpacks the heterogeneous effects on different occupational categories. In Section 6, we focus on the effects of NR skills on the wages of major occupational groups and productivity. The conclusions summarize and sketch future lines of research.

\section{Literature review}

Innovation studies have made significant contributions to the analysis of the relationships between knowledge, industry evolution and competitiveness. This paper focuses on one particular mechanism through which knowledge is applied to economic ends, namely, employment. Arguably, besides sporadic bursts of interest (e.g., Nelson and Phelps 1966; Freeman and Perez, 1988; Amendola and Vona, 2012; Consoli et al., 2013; Boschma et al., 2014), the workings of labor markets and the relationship between human labor and technology have not been fully integrated into the intellectual apparatus of innovation studies. However, employment is the pathway that permits the translation of human know-how into productive activities, and understanding what the mechanisms that influence changes in the employment structure are is the key to identifying which forms of know-how are relevant at any time and the role that technology plays in modifying this know-how.

We explore these issues by building on the task-based approach proposed by Autor, Levy and Murnane (2003) (ALM henceforth). In the perspective put forth by ALM, skills are 
ensembles of abilities applied to job tasks. The key intuition is that productive activities can be broken down into functionally different task groups and that technological change affects the comparative advantage of productive factors, i.e., workers and machines, in performing a certain task (Levy and Murnarne, 2004). This approach opens up new possibilities for understanding the process by which individual abilities emerge, combine, or are selected as a result of innovation and structural change; it is an appealing conceptual framework to address issues that are central to innovation studies. First, it allows for a more flexible interpretation of the relationship between labor and capital in performing work tasks, which is especially relevant in those contexts in which technology plays a dual role, partly complementing and partly substituting human work. Clearly, this approach is grounded in an interdisciplinary view whose central tenet, traceable to Herbert Simon (see e.g., 1969), holds that machines perform better physical and cognitive 'routine' tasks that can be codified in the form of instructions, while humans retain a cognitive comparative advantage at 'non-routine' activities that involve problem-solving, pattern recognition (e.g., Langlois, 2003) and personal interaction, such as communicating with others (interpersonal skills) or interpreting information (analytical skills). However, another advantage of the task-based approach is that it accommodates empirical findings of non-neutral labor market outcomes due to the diffusion of new general purpose technologies (GPTs) ${ }^{1}$ and associated changes in the organization of production for which the traditional capital-skill complementarity hypothesis (i.e., Krusell et al. 2000) does not suffice. ${ }^{2}$

\footnotetext{
${ }^{1}$ Note that the task-based also model suits other radical technological transitions, such as electrification in the $19^{\text {th }}$ century (Gray, 2013).

${ }^{2}$ Within the economics literature on the effect of ICT technologies on the labor markets, early studies generally explain the increase in the skill premium using a demand-supply framework augmented for directed technical change (see, e.g., Krueger et al., 1993, Katz and Murphy, 1992; Autor et al., 1998; Goldin and Katz, 1998; Acemoglu, 1998). This approach, however, is unable to explain polarization and has hence been replaced by the more general routinization hypothesis discussed in the main text (see Autor, Katz and Kerney, 2008). The debate is well summarized in Acemoglu and Autor (2011).
} 
Building on the review above, we propose an analysis of the determinants and effects of changes in the demand of non-routine (NR henceforth) skills in US manufacturing industries from 1999-2010. This time window is especially interesting due to the co-occurrence of key global events, such as China’s admission to the WTO and the great recession after 2007.

Previous studies on the determinants of change in the demand for skills draw attention to ICTs and trade. ALM (2003) first proposed that ICTs induced 'polarization' in employment and the demand for skills, that is, the decline of routine-intensive jobs and wages relative to occupations that are either at the top or at the bottom of the earning distribution (Autor et al., 2008; Goos and Manning, 2007). As discussed before, computer capital substitutes for routine tasks, thus reducing the demand for routine-intensive occupations, while increasing the productivity of non-routine analytical and interactive skills and thus the demand for highly skilled professionals. Interestingly, these empirical regularities also have been observed in a large panel of economies, not just in the US. ${ }^{3}$ Recent evidence also suggests that the influence of ICTs has waned over the last decade. Weber and Kauffman (2011), for example, note that ICT-related investments in US manufacturing plateaued during the 2000s, and that the lion's share of capital spending now goes into maintenance activities rather than new technology acquisition. Aizcorbe et al. (2006) also call attention to a break in the technological trajectory of ICTs sometime in the early 2000s that is ascribed to a combination of changes in economies of scale and a shift in the product mix. ${ }^{4}$ This shift, although not necessarily implying the reduced importance of technology, calls at least for a reconsideration of the one-to-one mapping between ICTs and NR skills. After all, it seems plausible that, after take-off and growth, the trajectory of ICTs may have reached a stage of

\footnotetext{
${ }^{3}$ See Spitz-Oener (2006); Goos et al. (2009); Acemoglu and Autor (2011); Jaimovich and Siu (2012).

${ }^{4}$ See also Oliner and Sichel (2000), Wolff (2003) and Basu and Fernald (2007). To illustrate, the product cycle for semiconductors (i.e., the lag between successive releases) has shifted back to a 3-year period since 2000 (Jorgenson et al., 2008) after being reduced to a 2-year period during the intense competition of the mid-1990s. Recent examples of ICT diversification also confirm this shift, e.g., Hubbard (2003) and Athey and Stern (2002).
} 
maturity and, as codification has caught up with the skills that pushed the technological frontier in the 1990s (Vona and Consoli, 2015), the dynamics of both productivity and wages have adapted accordingly. The first goal of the paper is to take stock of existing evidence and assess whether technology continued to be a major driver of the demand for skills during the 2000s; in particular, this paper seeks to determine whether technology has spurred any further divergence across occupations and industries.

The debate on the changes in the skill content of the workforce has been recently enriched by the inclusion of trade as a key explanatory factor. Trade’s inclusion is not surprising considering the remarkable pace of expansion of China and of various emerging economies that have transformed the global import-export matrix (Hanson, 2012). With regard to the US, the general agreement is that higher exposure to foreign competition had a negative employment effect, especially after China’s entry into the WTO in 2001 (Pierce and Schott, 2012; Autor et al., 2013). The literature draws attention to two mechanisms. On the one hand, the greater fragmentation of supply chains (Baldwin, 2011) has opened up the scope for offshoring routine tasks involving minimal complexity (Blinder, 2009). On the other hand, domestic producers have reacted to foreign competition by switching to higher quality products and innovations that require the intensive use of non-routine tasks (Verhoogen, 2008). In general, much empirical evidence lends support to the conjecture that the impact of trade has been heterogeneous across industries and occupations. ${ }^{5}$ With the notable exception of Lu and Ng (2013), however, few have analyzed the impact of trade on the skill content of US industries during the large increase of trade with low-wage and emerging countries. Addressing this issue is the second objective of this paper.

\footnotetext{
${ }^{5}$ Note that large trade shocks are not limited to the US; empirical evidence shows a direct effect of trade shocks on returns to skills in both developing (Verhoogen, 2008; Amiti and Davis, 2012) and developed countries (Guadalupe, 2007; Raitano and Vona, 2013). Bugamelli et al. (2008) find that the Euro and increased competition from China induced restructuring in the workforce composition, especially among low-tech sectors.
} 
By tackling the two questions outlined above, this study adds to previous literature in two ways. First, it focuses both on the determinants of the demand for NR skills and the effects of NR skills on performance, as captured through changes in industry wages and productivity. Second, studies on the determinants of NR skills (Autor et al., 2003; Lu and Ng, 2013) arguably neglect the dynamic process through which the composition of the workforce gradually adapts to a new, ex ante undetermined, target level of NR skills. Our empirical strategy accounts for this adaptation process using standard system-GMM techniques. We believe that these techniques are the appropriate, as technological revolutions induce a dynamic response in the employment structure and the attendant know-how (Autor et al., 2003; Vona and Consoli, 2015).

\section{Empirical strategy}

Let us now illustrate our empirical strategy. To fix ideas, we are primarily interested in explaining non-routine skill intensity at time $t$ in industry $i\left(\mathrm{NRI}_{\mathrm{it}}\right)$ as a linear function of trade and technology variables. In the second part of the paper, we focus on an indicator of performance $Y$ as a function of $N R$ intensity, trade and technology proxies, as shown in the following formulae:

$$
\begin{gathered}
N R I_{i t}=f\left(\text { trade }_{i t}, \text { tec }_{i t}\right) \\
Y_{i t}=f\left(\text { trade }_{i t}, \text { tec }_{i t}, N R I_{i t}\right)
\end{gathered}
$$

Assuming the linearity of $f($.$) is not just for the sake of simplicity. This paper is mainly an$ empirical exercise and relies on previous work to derive testable predictions; therefore, we do not present theoretical justifications in support of including interactions or nonlinear effects. In addition, relevant literature keeps the empirical specification to a minimum to avoid a misinterpretation of the effects of interest. Accordingly, we opt for a parsimonious specification. In the studies of Autor et al. (2003) and Lu and Ng (2013), the identification of 
the effects of interest is warranted through the inclusion of unobservable individual effects and/or through the use of IV. An IV approach would be appealing for us because unobservable time-varying factors likely affect both the demand for NR skills and the evolution of technology. However, previous works have been unsuccessful in finding appropriate instruments for both trade and technology proxies. For example, Autor and Dorn (2013) and Autor, Dorn and Hanson (2013) use NR skill levels in the 1950s as instruments for NR skill levels to explain the changes in employment shares across occupational groups in later decades. This empirical strategy has the problem that instruments based on initial conditions are suitable for explaining the demand for NR skills in the 1960s but lose explanatory power in the following decades, thus becoming weak predictors for the crucial decade of the ICT revolution.

Another important source of bias is true state dependence in the data generating process. In our case, the 0.97 point estimate of the autocorrelation coefficient for NR skills indicates that state dependence characterizes the adjustment in the industry demand for NR skills. ${ }^{6}$ Such a high degree of persistence is not surprising considering that both the demand for and the supply of skills are variables that change slowly over time. Demand changes slowly because of non-negligible hiring and firing costs due to skill specificity; supply changes slowly because there are significant lags in the adjustment through training and education. Note thatin past work, e.g., ALM (2003), state dependency may have been less severe because the time unit was a decade or a 5-year period. More recently, Lu and Ng (2013) used an industryby-year panel and correctly concluded that their findings do not change when dynamics are properly accounted for. However, their point estimates for the effect of the lagged dependent variable range between 0.05 and 0.15 , well below that of our data. ${ }^{7}$ A similar argument

\footnotetext{
${ }^{6}$ Similar results emerge when using standard tests for serial correlation and presence of unit roots.

${ }^{7}$ High persistence is also observed when using the measures of NR skills of Lu and Ng (2013). The latter study uses differenced GMM (Arellano and Bond, 1991) instead of the more general system GMM (Blundell and
} 
applies to our measures of performance, i.e., industry wages and productivity, which also exhibit high persistence with estimated autocorrelation coefficients above 0.9. Therefore, our specifications in eq. 1-2 are as follows:

$$
\begin{aligned}
& N R I_{i, t}=\rho N R I_{i, t-1}+\beta_{1} \text { tec }_{i, t-1}+\beta_{2} \text { trade }_{i, t-3}+\mu_{i}+\mu_{t}+\varepsilon_{i, t} \\
& Y_{i, t-1}=\rho Y_{i, t-1}+\alpha_{1} N R I_{i, t-1}+\alpha_{2} \text { tec }_{i, t-1}+\alpha_{3} \text { trade }_{i, t-3}+\mu_{i}+\mu_{t}+\varepsilon_{i, t},
\end{aligned}
$$

where $\mu_{i}, \mu_{t}$ and $\varepsilon_{i, t}$ are an industry effect, a time effect and a generic disturbance term, respectively. While it is well-known that OLS and fixed-effect estimators deliver biased estimates of the effects of interest under these circumstances (Nickell, 1981), the debate on what is the best fix is still open. The system-GMM estimator (Arellano and Bover, 1995; Blundell and Bond, 1998) has gained some consensus among applied economists. The basic rationale underpinning these estimators is the use of a lagged dependent variable with its lags or lagged differences. Within this class of estimators, the system GMM reduces the smallsample bias of the difference GMM (Arellano and Bond, 1991) when the endogenous variables are persistent, using moment conditions both for the equation in level and in firstdifferences (Bond, 2002). Such a bias exists because the pure random disturbance generated when differencing a persistent variable is, by definition, a weak instrument.

The inclusion of the lagged dependent variables does not fully address the endogeneity of trade and technology variables, even if the lagged dependent variable is a good proxy for industry-time-varying factors that are likely to bias our effects of interest. For technology, we exploit the long data series available for our technology proxy and use past values as proxies for current ones. For trade variables, we could have followed the same route, but we would lost two years for our analysis because trade variables are only available until 2007. We therefore opted for including trade variables with a 3-year lag to avoid the problem of having

Bond 1998), which we argue may generate a downward bias of the autocorrelation coefficient. Using a Montecarlo experiment, Hauk and Wacziarg (2009) show that the differenced GMM tends to considerably underestimate the autocorrelation coefficient compared with a system GMM estimator. 
‘too many instruments’ compared with the number of observations (Roodman 2009a).

Likewise, because available data for technology are only available until 2009, we lag our technology proxy. This peculiar lag structure is the best option for preserving an acceptable time span in the analysis of the 2000s, and for ensuring the inclusion of the recent economic recession. $^{8}$

Further details of the empirical strategy are outlined in the results section. ${ }^{9}$ Let us now illustrate the dataset and the construction of the variables.

\section{Data and variables}

Our empirical analysis combines data from three different sources. We use US Bureau of Labor Services (BLS) data for employment and hourly wages across industries (four-digit occupations based on the Standard Occupational Classification System, henceforth SOC) and four-digit NAICS. The latter is matched with information on occupation-specific task content, the O-NET abilities survey of the US Department of Labor. Lastly, we use NBER data for variables on international trade data, technology, productivity and the remaining controls. Data construction and measurements are detailed below, while further details are provided in the online appendix.

\section{Construction of task variables}

The US Department of Labor's O-NET abilities survey is the main source of information to compute our task variables. This database gathers information on worker attributes and job characteristics from questionnaires aimed at both job incumbents and occupational analysts

\footnotetext{
${ }^{8}$ Interestingly, the financial crisis of 2007 has no significant effect on our variables of interest. The same holds when we include proxies for industry demand. Our results are also robust to changes in the lag structure, which is not surprising because our explanatory variables are also highly persistent.

${ }^{9}$ Our model is mostly focused on changes due to technological effects. In so doing, we do not consider other factors affecting demand and supply conditions, such as the minimum wage. This focus is plausible because no significant institutional changes occurred in the period analyzed, and we believe that fixed effects are enough to control for any effect related to any such changes. We would like to thank an anonymous referee for calling our attention to this point.
} 
(see Tippins and Hilton, 2010). To keep up with changes in the US labor market, O-NET data are regularly updated and adapted in a way that includes two sources of variation for the task content: (i) occupations are added, reclassified or eliminated in accordance with periodical revisions in the SOC structure, and (ii) the scores of worker characteristics increase or decrease as a result of their changed importance. We kept track of all revisions from 20022010 and created a unique dataset of 855 four-digit SOC occupations. O-NET information on job content has been matched with industry-occupation total employment from the BLS for the $1999-2010$ period. ${ }^{10}$ Because the first usable wave of O-NET is from 2002, we lack information on employee abilities in the 1999-2001 period. To cope with this lack of information, we assign time invariant from the 2002 wave of O-NET to observations that belong to the 1999-2001 period. Using crosswalks across different datasets, we obtain a balanced industry-by-year panel dataset, which includes 86 manufacturing industries for the period 1999-2010.

The key dimensions for our variables of interest are job-specific characteristics, such as communicating with others (NR interactive), interpreting the meaning of information (NR cognitive), performing administrative activities (routine cognitive), and performing physical activities (routine manual); please see further details in the online appendix. Accordingly, the scores assigned based on survey responses generate vectors of basic tasks that are specific to each SOC occupation. Although such basic tasks are common to most jobs, a particular combination of scores in the use of each task distinguishes one occupation from another.

Our task constructs are built from a detailed examination of O-NET work activities and work contexts, i.e., the scores for basic tasks. These items are subsequently grouped together in four main macro-categories: non-routine cognitive (NRC), non-routine interactive (NRI),

\footnotetext{
${ }^{10}$ BLS data on employment for the 1999-2010 period are based on different industry classification schemes: the 1987 Standard Industrial Classification (SIC1987) until 2001, the 2002 North American Industry Classification System (NAICS) until 2006, and the 2007 North American Industry Classification System (NAICS) currently in use. We developed concordance tables, the details of which appear in Section B1 of the appendix.
} 
routine cognitive (RC) and routine manual (RM). Table B1 in the appendix lists the $40 \mathrm{O}-$ NET task items used in this study, ten for each macro-category. The macro-categories are computed by adding up the score of importance for a particular SOC occupation. The index of task intensity is as follows:

$$
N R \text { Intensity }_{i t}=\sum_{j} \text { Emp Share }_{i j t} *\left[\frac{N R C+N R I}{R M+R C}\right]_{i j t},
$$

where NRC, NRI, RM and RC are the task constructs outlined above for industry $i$ and

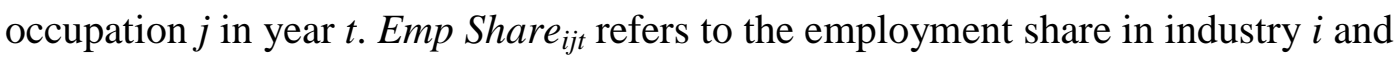
occupation $j$ in year $t$, which is constructed using data for the four-digit NAICS and four-digit SOC from the BLS. To define skill categories, we build on the classification of Acemoglu and Autor (2011) by including additional items (see Table B1 in the appendix). Moreover, we partially depart from previous literature because our measure is not the employment share of occupations ranked according to initial levels of non-routine skill content (see Autor et al. 2013); we instead use an industry-level measure of non-routine skills. We believe that this is a first step towards a fully dynamic account of the process analyzed. ${ }^{11}$

Furthermore, to capture heterogeneity in the effect of our variables of interest across occupations, we follow Autor and Dorn (2013) and differentiate between three broad occupational groups. The first category, which includes occupations that are intensive in terms of non-routine tasks (NRI and NRC), is labeled as the high-skill (henceforth HS) group. The second category encompasses routine-task-intensive activities and contains medium-skill (henceforth MS) occupations. The last group features low-skill jobs and includes low-skill (LS henceforth) occupations. Similar to what was done for the task measure above, we create

\footnotetext{
${ }^{11}$ We performed several checks based on different measures of task content at the industry level. The interested reader is referred to the appendix of the working paper version of the present study: https://www.sussex.ac.uk/webteam/gateway/file.php?name=2014-18-consolivonarentocchini.pdf\&site=25
} 
three different task measures referring to the three broad occupational categories: high skill (NR intensity HS), medium skill (NR intensity MS) and low skill (NR intensity LS). ${ }^{12}$

\section{Labor productivity and hourly wage measures}

We analyze the effects of changes in non-routine tasks by focusing on labor productivity and hourly wages. The former is an aggregate (industry-level) measure of performance, while the latter varies across occupations and thus provides useful insights into the impact of our variable of interest, NR intensity, over different types of workers. Labor productivity (Prod ${ }_{i t}$ ) is computed as the value added per worker at the four-digit NAICS; it is the total value added in \$ million per 1,000 employees and is available on a yearly basis for the 1989-2009 period. Information on total value added and employment is extracted from the NBER-CES manufacturing industry database (Becker and Gray, 2013). The source of the other performance indicator, the average hourly wage for four-digit occupations, is the BLS. Following the same logic underlying the construction of the task measures, we seek to capture heterogeneity across the three occupational categories by considering group-specific hourly wages, namely, Wage HS, Wage MS and Wage LS. ${ }^{13}$

\section{Measures of technology and trade}

We represent investments in ICTs using the information on the investment in capital equipment per worker available from the NBER-CES Manufacturing Industry database (Becker and Gray, 2013). This simple measure is appropriate for our purposes considering the vast literature on the pervasiveness of automated processes in production technology (e.g., David and Wright, 2003; Brynjolfsson and McAfee, 2011) and their capacity to capture embodied technical change (Cummins and Violante, 2002).

\footnotetext{
${ }^{12}$ All task measures are aggregated in the occupational group by weighting for the employment shares of each occupation belonging to the group.

${ }^{13}$ The aggregate hourly wage at the occupational group level is weighed by employment shares.
} 
We measure exposure to trade using an index of import penetration that is widely used in the literature (Bernard et al., 2006; Lu and Ng, 2013). Import penetration ratios are a reliable measure of the evolution in the exposure of manufacturing industries to foreign competition. Accordingly, we define two measures of import penetration. Imp Pen Hi-Med ${ }_{i t}$ is the ratio of the total value of US imports from high- and medium-wage countries to the total value of shipments and imports minus exports. To capture the effects coming from low-wage countries, we also define import penetration from low-wage countries (Imp Pen Low) ${ }^{14}$ and from China (Imp Pen China). To construct our measures, we employ US import and export data for the manufacturing industries for the 1996-2007 period, as compiled by Peter Schott, and data on the value of shipments from the NBER-CES manufacturing industry database.

Figure 1 shows the prolonged contraction in US manufacturing employment with two sharp accelerations coinciding with the recessionary phases of 1999-2003 and 2007-2010. Note that on both occasions, the contraction has been stronger for MS and LS occupations relative to HS occupations.

\section{[FIGURE ONE ABOUT HERE]}

Table 1 presents basic statistics with details on the reference period and the data source. Figure 2 offers preliminary insights into the relationship between the relative demand for skilled labor and our main explanatory variables, namely, capital equipment and import penetration, over time. We observe that import penetration from low-wage countries accelerates faster than import penetration from high- and middle-income countries, especially after 2001 [cf. quadrants (b) and (c)]. Incidentally, this pattern is very much driven by trade with China [quadrant (d)].

\footnotetext{
${ }^{14}$ Low-wage countries are those with a GDP per capita less than 5\% of US per GDP per capita.
} 
Figure 3 shows the smoothed change of NR skill intensity across all sectors ordered by the initial NR intensity in the analyzed period. The decreasing shape shows that skill growth was faster for industries with lower initial NR intensity, thus providing a first insight into crossindustry convergence.

[FIGURE 2 ABOUT HERE

[FIGURE 3 ABOUT HERE]

[Table 1 ABOUT HERE]

Let us now turn to the analysis of the determinants and the effects of changes in the demand for non-routine skills.

\section{Determinants of non-routine skills}

This section presents the analysis of the demand of NR skills at the industry level. Table 2 shows the baseline results. These results are extended in Table 3 by allowing heterogeneity across different occupational groups. To ease the interpretation, recall that our measure of NR skills is basically tantamount to a general measure of employment quality.

\section{Baseline specification}

Table 2 shows a series of specifications that are progressively enriched by various controls. The common covariates are the lagged dependent variable, lagged capital equipment, our chosen proxy for ICTs, Cap Equip, and two time-invariant dummies for low- and mediumtech industries (Low Tech and Med Tech, respectively). ${ }^{15}$ Both lagged capital equipment and the lagged dependent variable are used: the former with the second lag and the latter with lags from 2 to 5 . Four preliminary observations are in order. First, standard tests validate our

\footnotetext{
15 To control for the technological content of different industry aggregations we use three dummies for the low (Low Tech), medium (Med Tech) and high (High Tech) technology sectors in manufacturing (according to the Eurostat classification). For further details, see Table B3 in the online appendix.
} 
specification: the Hansen test does not reject the null hypothesis of instruments' exogeneity, and the Arellano-Bond tests always fail to reject the alternative hypothesis of second-order autocorrelation. ${ }^{16}$ The validity of the standard specification tests applies to all the models presented in the remainder of the paper. Second, dynamic specifications reduce the bias of the estimated effects, especially for capital equipment. This is evident from a comparison between Table 2 and Table A1 in the appendix, where the main specifications (Model 1 and 3) are estimated using OLS and FE without the lagged dependent variable. Third, the effects of the lagged dependent variable $\hat{\rho}$ (well above 0.9) and of the two dummies Med Tech and Low Tech (negative relative to the reference category, High Tech) point to high persistence in the adaptation process for NR skill intensity. Model 1 uses only Cap Equip as an external explanatory variable. This specification is akin to the specification of the classic ALM (2003) paper, with the exception of the lagged dependent variable. The point estimate is positive but not significantly different from zero (p-value=0.348), which indicates that the aggregate effect of ICT adoption on non-routine skills weakened over the last decade. The specification of Model 2 includes trade with high- and medium-wage countries and is equivalent to the model used by Lu and Ng (2013) augmented with the lagged dependent variable. Our results corroborate their finding of a positive and significant effect of import penetration on the skill quality of the workforce over the 1999-2010 period. In Model 3, our favorite specification, the effect of trade is broken down by considering the import penetration from low-wage countries. Unlike Lu and Ng (2013), we find that the positive and significant effect of trade with high- and medium-wage countries is totally absorbed by Imp Pen Low. ${ }^{17}$

The inclusion of Imp Pen Low yields a twofold increase in the capital equipment coefficient, which is now statistically significant at a $95 \%$ level. Although the correlation between Imp

\footnotetext{
${ }^{16}$ The difference Sargan test (not shown here) generally confirms that system GMM is the appropriate specification compared with differenced GMM.

${ }^{17}$ Table A2 in the appendix shows that the main results of Model 3 are confirmed using the between estimator suggested by Hauk and Wacziarg (2009), which is more robust for measurement errors than the system GMM.
} 
Pen Low and Cap Equip is rather modest at -0.17, industries with higher exposure to trade from low-wage countries likely adjust not only their labor force skills but also their use of complementary inputs, such as capital equipment. Model 3a and 3b address this issue by reestimating the Model 3 split for industries below and above the pre-sample median of the initial level of Imp Pen Low, respectively, for 1989-1995. The results are striking: while the point estimate of Imp Pen Low (resp. Cap Equip) is statistically significant (resp. insignificant) only in industries highly exposed to the competition of developing countries, the opposite holds for Cap Equip (resp. Imp Pen Low). Interestingly, the Cap Equip coefficient is much higher in industries with high exposure to Imp Pen Low, but it displays a high variability, which makes it statistically insignificant. This finding is broadly consistent with the finding of Autor, Dorn and Hanson (2013) that the effects of trade from low-wage countries and of technology do not overlap. We therefore conclude that differences in the effect of technology across industries may not be visible unless imports from low-wage countries are taken into account.

The statistical significance of the estimated effects may not correspond to economic significance. However, in this case, the size of the two short-run effects of Cap Equip and Imp Pen Low reflects the increasing importance of the latter relative to the former. In particular, a one standard deviation increase in Cap Equip (resp. Imp Pen Low) explains 2.1\% (resp. 3.6\%) of a standard deviation in NR intensity. ${ }^{18}$ Note that the long-term effects of these two variables are considerably larger, i.e., more than 11 times larger, than the short-term effects. $^{19}$

\section{[Table 2 ABOUT HERE]}

\footnotetext{
${ }^{18}$ A possible objection is that the effect of Imp Pen Low is reduced by the particular lag structure chosen (see Section 2). To check for this possibility, we replicate the analysis using a shorter lag structure and find that both the size and the statistical significance of the estimated coefficients are fully consistent with those of Model 3. The results are available upon request.

${ }^{19}$ The long-run effect is equal to the short-run effect multiplied by $1 /(1-\rho)$, where $\rho$ is the estimated autocorrelation coefficient.
} 
The descriptive analysis in Figure 3 may suggest a mild tendency towards the industry catching up in the level of NR skills. However, the high values of the autocorrelation coefficient for NR intensity together with the negative and statistically significant coefficients of the Low Tech and Med Tech dummies in Table 2 imply considerable persistence in the demand for NR skills. We investigate this tendency by splitting the sample using the median of the initial level of NR skill intensity and excluding the Low Tech and Med Tech dummies. Models 3c and 3d illustrate that Imp Pen Low and Cap Equip have a large and statistically significant effect only in industries with a below-median initial skill level. In turn, the positive and near significant (p-value=0.138) effect of Imp Pen Hi-Med in skilled industries is offset by a negative and significant effect in unskilled industries. In sum, at the industry level, trade from low-wage countries and technology emerge as the strongest convergence force for NR skills, while trade with high-wage countries is a mild source of divergence.

In sum, two major findings stand out so far. First, Imp Pen Low induces restructuring and skill adaptation, especially in LS industries that are arguably more exposed to competition from low-wage countries. The fact that the adjustment to foreign competition depends on the initial skill level and is a source of skill convergence across industries is in line with previous studies on European countries (Bugamelli et al., 2008) and the US (Pierce and Schott, 2012). Second, technology, represented by capital equipment, is not a source of skill divergence; it is instead a source of mild cross-industry convergence. This finding suggests that as ICTs have matured and their activities have been codified, the impact of technology may have faded away (Vona and Consoli, 2015).

\section{Heterogeneity in occupational skill content}

Models 1-3 in Table 3 replicate the analysis of Table 2 by allowing for heterogeneity across the three previously defined occupational categories. As expected from the employment 
patterns depicted in Figure 1, the results reveal substantial heterogeneity across occupational groups. First, skill persistence, captured by the lagged NR occupation-specific coefficient is stronger for supervised occupations, viz. LS and MS, relative to HS occupations. In regards to our main explanatory variables, Imp Pen Hi-Med has a negative and significant effect on LS but a positive effect on the other occupations. Taking into account significance levels and considering the results for the above-median split sample of Table 2, we conclude that Imp Pen Hi-Med is a source of skill divergence mainly between MS and LS occupations. Second, in accordance with ALM (2003), Cap Equip continues to exert a polarizing effect because skill upgrading is stronger for HS and LS occupations compared with MS occupations. Third, Imp Pen Low is also a source of significant skill polarization. This result, in line with the Heckscher-Ohlin model, suggests that trade is a source of inequality in terms of the use of certain inputs or tasks, in this case non-routine tasks, especially between countries with very large differences in endowments. For LS occupations, the net effect depends on the direction of the adjustments that follow trade-induced job loss. ${ }^{20}$ On the whole, the share of LS occupations will be lower but the surviving workers will be more qualified.

\section{[Table 3 ABOUT HERE]}

Models 4-6 in Table 3 further articulate the effect of trade by breaking down Imp Pen Low into two import penetration ratios, thus isolating imports from China (Imp Pen China) from those of other low-income countries (Imp Pen Low No China). Imp Pen China has a positive effect on all groups, especially the HS group, for which the effect is also statistically significant. The coefficient for the HS category is in line with earlier remarks on the fragmentation of production chains (Baldwin, 2011) and the comparative advantage that

\footnotetext{
${ }^{20}$ For the sake of space, we do not report results for employment that are consistent with the literature. In particular, Imp Pen Low has a negative, large and significant effect on the employment of LS workers. A recent study by Autor, Dorn, Hanson and Song (2013) finds that workers initially employed in industries with higher exposure to Chinese competition are more likely to change jobs and move out of manufacturing altogether; high-wage workers are able to relocate before large-scale restructuring occurs and thus avoid significant earning losses, while low-wage workers, who are generally less mobile, are more likely to be laid off.
} 
countries such as China have gained in labor-intensive sub-activities within high-tech industries (Krugman, 2008; Hanson, 2012). In particular, the demand of NR skills is expected to increase, especially among HS occupations, as a result of the offshoring of routine-taskintensive jobs to low-wage countries. The positive effect of Imp Pen Low on the NR skills among LS occupations is fully captured by the effect of other low-wage countries, except for China. This finding is consistent with recent evidence on the shift from LS to MS production in China (Amiti and Freund, 2010). The selection effect on the quality of the workforce in LS occupations should be stronger for low-wage countries that remain specialized in LS production.

Note that the results are qualitatively confirmed by the use of the BE estimator (see Table A2 in Appendix A). These findings also suggest a substantially heterogeneous effect of trade and technology across occupational groups, which is further corroborated by the graphical analysis on the differences between the estimated coefficients (see Figure A1 and A2 in the online appendix).

\section{The effects of NR skills}

This section presents the analysis of the effects of NR skills in terms of industry-level performance, which is divided into two parts. The first part focuses on productivity, and the second part focuses on wages.

\section{Productivity}

Table 4 shows the results for the analysis of productivity growth, which is measured as the value added per worker. To take into account the dynamic nature of the process, our estimations are based on system GMM. ${ }^{21}$ In particular, we use a catching-up equation (e.g., Griffith et al., 2004) in which the dynamic term is the lagged distance-to-frontier effect,

\footnotetext{
${ }^{21}$ As in the case of the skills described above, standard statistical tests corroborate the validity of our choice.
} 
which is computed as the difference between each industry's productivity of and that of the most productive industry divided by the latter's productivity (Distance to frontier). ${ }^{22}$ The inclusion of the distance-to-frontier term allows the modeling of productivity dynamics as dependent on the scope of the catching up of the specific industry at stake (Nicoletti and Scarpetta, 2003). All variables are in log to allow for a direct interpretation of the effects in terms of elasticity.

\section{Table 4 ABOUT HERE}

The first specification, Model 1, shows that the effect of skill upgrading is, as expected, positive and statistically significant. In particular, a $1 \%$ increase in the intensity of $N R$ intensity yields a $0.18 \%$ increase in productivity. Note that this effect is akin to a short-term effect because it is obtained by controlling for the distance-to-frontier term. The distance-tofrontier coefficient suggests cross-industry convergence with a large effect of $6.8 \%$ catchingup on a yearly basis. Our catching-up specification for productivity dynamics captures faster productivity growth in industries with lower initial levels, as the positive sign of the dummies for middle- and low-tech industries confirms. However, this specification suffers from an omitted variable bias, as many other sources of productivity growth are not included. We address this shortcoming by including various proxies for skills and other drivers of productivity.

The addition of the industry employment shares of HS and MS, using LS as 'reference group’, to Model 2 reverses the result for NR intensity, which is now negative. In turn, higher shares of HS and MS workers are observed to have positive productivity effects with shortterm elasticity $(0.15 \%$ and $0.1 \%$, respectively). This finding suggests that the relative quantity

\footnotetext{
${ }^{22}$ We use information from our productivity measure and define the productivity distance in sector $i$ and year $t$ as the value of the most productive industry in year $t$ : Max(Prod) $)_{\text {. }}$
} 
of HS workers matters more than the relative quality of the workforce for industry productivity growth.

To further elucidate the catching up, the sample is split into two groups according to initial productivity levels, above (Model 2a) and below (Model 2b) the median productivity of the pre-sample period, 1990-1998. Observe that catching up is concentrated in industries above the median productivity level. Because the distribution of value added per capita is rightskewed, industries with average productivity levels catch up with those at the frontier. The next step includes other productivity drivers selected on the basis of previous studies. The specification in Model 3 includes Cap Equip and the usual proxies of international competition. Both sets of variables are expected to positively affect productivity growth. The former effect derives straightforwardly from any endogenous growth models, while the latter depends on firm selection in new trade models à la Melitz (2003). First, we observe that the effect of $N R$ intensity is again negative and near significant (p-value=0.130), while the elasticities associated with Emp Sh HS and Emp Sh MS increase above 0.2. Second, as expected, the Cap Equip coefficient is positive and statistically significant with a modest short-term elasticity of 0.01 . Third, the two measures of import penetration have no particular influence on productivity. If any, the influence of trade tends to be negative.

Comparing these results with the existing literature, these technology-related results resonate with evidence on the positive impact of ICTs on industry productivity (Siegel and Griliches, 1992; Jorgenson et al., 2008). For trade, the effect is not in line with new trade models à la Melitz (2003), and it is important to note that this last set of results is not always robust to the use of a robust BE estimator (see Appendix). Finally, the finding on the effect of NR skills is consistent with the study of Wolff (2003), showing that growth in cognitive skills has a positive, albeit modest, association with industry productivity growth. Reassuringly, this 
main result on the effect of NR skills on productivity is robust to changes in specifications and to different productivity measures. ${ }^{23}$

\section{Industry wages}

Wage changes are frequently used in the study of the dynamics of skills and employment. The existing literature extensively analyzes the effect of routinization and trade on wage inequality, i.e., the wage difference between higher and lower occupations. The usual assumption is to rank occupations according to their initial skill levels, so that the effect of interest is not skill upgrading on wages but rather trade and technology on wages mediated by the initial skill level. In this section, we address a complementary research question: how much do wages react to upgrading an occupation's NR skill content? Wages are interpreted here as a measure of economic performance at the occupational level. ${ }^{24}$ This shift in perspective is possible because our dataset allows us to create skill measures for occupational macro-groups that vary over time and across industries. ${ }^{25}$ All things being equal, we expect that workers with higher NR intensity values will be paid more.

The evolution of the wages of occupation $i$ in industry $j$ is characterized by true state dependency, which leads us to adopt, for the same reasons discussed earlier in regard to $N R$ intensity, a dynamic specification. However, the lagged dependent variable is not normally included in the standard Mincerian wage equation. Hence, in Table 5, we compare two main specifications for wages: the baseline model with industry fixed effects, but without dynamics (Models 1-3), and our favorite dynamic specification, estimated with system GMM

\footnotetext{
${ }^{23}$ In particular, it is robust to a classic dynamic specification rather than to a catching-up specification, a BE estimator (Table A2 in Appendix A) and different measures of productivity growth (TFP and output per worker).

${ }^{24}$ This interpretation fits well with the institutional features of the US labor market, in particular decentralized bargaining and flexible wage setting.

${ }^{25}$ Recall from Section 2 that the skill intensity of each occupational macro-group varies across sectors, as the employment shares of each elementary SOC occupation vary by sector. Note that occupational macro-groups are an aggregate of elementary SOC occupations.
} 
(Models 4-6). Here we instrument the lagged dependent variable, the occupational-specific level of NR intensity and its share of employment. Again, all variables are in log to interpret the effects in terms of elasticity.

Models 1-3 in Table 5 show that the effect of NR intensity is positive and statistically significant across all occupational groups. However, the estimated elasticity is decreasing in the occupational ranking and is significantly lower for LS occupations. Additionally, Emp HS has a positive wage effect for clerks (p-value=0.10), even more so for lower occupations. Conversely, Emp MS is associated with a statistically significant wage penalty for all occupational groups. The effect of Cap Equip is not in line with our previous findings on skill demand: equipment magnifies the wage gap between HS and MS occupations relative to LS occupations. The effect of trade is statistically insignificant for HS and MS occupations, while it is negative for LS occupations, where the Imp Pen Hi-Med coefficient is also statistically significant.

\section{Table 5 ABOUT HERE}

Models 4-6 in Table 5 are our favorite dynamic specifications. The first noticeable difference with the static model is that the effect of $N R$ intensity only remains significantly different from zero for HS occupations. The effect is also quite large, with an elasticity equal to 0.45 in the short-term and 2.1 in the long-term. The coefficient associated with the employment share of HS is now positive and significant only for HS and MS occupations, while that of LS occupations disappears. In general, the effects of non-routine skills on wages appear to increase with occupational quality. Similar to what was observed for the determinants of $N R$ intensity, wage persistence appears to decrease with occupational quality.

Compared with Models 1-3, the new specifications yield clearer results for the remaining explanatory variables. Cap Equip has a positive wage effect on all occupations. While the 
short-run elasticity seems only slightly higher for LS occupations, the long-term effect is much higher: 0.13 compared with 0.04 for HS and MS occupations. Trade with high- and medium-wage countries is associated with a higher wage premium for HS occupations, which is consistent with our findings for NR intensity. The effect is modest but not small, with a long-term elasticity of 0.23. Finally, Imp Pen Low has a near significant (p-value=0.152) negative effect on only LS workers, with a long-term elasticity of 0.33 . However, similar to what we noted in regard to productivity, the effects of trade on wages are not very robust to the use of the BE estimator, while the other variables remain qualitatively unaffected (Table A3 in online appendix).

The modest and unclear wage effect of trade is accounted by two effects that tend to cancel out at the macro level. On the one hand, a contraction in employment entails a selection effect that favors the best workers' survival and increases their average productivity and, in turn, their wages. On the other hand, lower bargaining power compresses the wages of continuing workers. Overall, these findings are in line with other industry-level studies showing that trade competition has had little impact on US manufacturing wages (Edwards and Lawrence, 2010; Ebenstein et al., 2013).

\section{Concluding remarks and future research}

This paper has elaborated an empirical analysis of changes in the skill content of occupations in US manufacturing industries over the 1999-2010 period. Following the seminal work of Autor, Levy and Murnane (2003) we adopt a task-based approach to analyze the determinants and the effects of changes in the demand of non-routine skills. The ALM study and the subsequent literature conclude that the diffusion of computing technology in the 1990s augmented the productivity of occupations requiring high levels of interactive and analytical skills to the detriment of routine-task intensive occupations. Such a process, in turn, gave way to significant divergences within and between occupations and industries. The first goal of 
the paper was to assess whether technology continued to be a source of divergence throughout the 2000s. We also acknowledge the prominence of other global forces, in particular the remarkable transformation of the global import-export matrix due to the expansion of international trade with China and other emerging economies. Accordingly, the second goal of the paper was to gauge the impact of trade on the skill content of US occupations and industries after the increase in trade with low-wage and emerging countries.

Our analysis yields three main results. First, import competition from low-wage countries has induced skill adaptation in LS industries that are arguably more exposed to foreign competition. In general, compared with technology, trade emerges as a stronger driver of demand for non-routine skills during the 2000s. The second key finding is that both technology and imports from low-wage countries have induced skill convergence across industries not due to convergence across occupations. Indeed, both technology and trade with low-wage countries induce stronger skill upgrading for HS and LS occupations and, in turn, a polarization effect. The last result is in line with previous literature and confirms that higher non-routine skills have overall modest effects on both productivity and wages, except for in HS occupations.

Looking ahead, the limitations and omissions of this study are a compass for future research on these issues. To keep things simple, we opted for an admittedly uncomplicated portrayal of technology, which leaves plenty of room for a richer characterization. One step in this direction is the exploration of a notion that has been mentioned but not fully developed here, namely, that technology evolves and that different stages of the life-cycle significantly influence the relevance of the skills that are necessary to use technology (Vona and Consoli, 2015). Second, the data available to us cover a time span that is too short to disentangle the changes in employment shares between occupations from the changes in task content within occupations. Such an analysis would mark an important step towards understanding the 
evolution of occupations beyond mere structural changes. Yet another promising departure from the present paper would be an analysis of the origin of new educational programs. In a truly dynamic process, the short-run imbalances triggered by trade and technology on the demand for skills are expected to stimulate the creation of educational packages aimed at facilitating the diffusion of new skills. In this spirit, our future research will focus on the evolution of formal education and training in response to changing demand for particular skills.

\section{Acknowledgements}

Early versions of this paper were presented at the EMAEE Conference (Skema Business School, Nice), at the seminar Economics of Innovation and Knowledge (Collegio Carlo Alberto, Turin) and at the SPRU Wednesday Seminar series (Brighton). We are grateful to attendants of these events for thought-provoking comments. We would also like to thank the guest editors and two anonymous referees for constructive criticisms and suggestions. We are solely responsible for all errors and omissions. DC acknowledges the financial support of the Spanish Ministerio de Economia y Competitividad (RYC-2011-07888). DC would also like to thank Antonia Díaz, María Paz Espinosa and Sjaak Hurkens for setting an example of professional ethics.

\section{Bibliography}

Acemoglu, D. (1999) "Changes in unemployment and wage inequality: An alternative theory and some evidence”. American Economic Review 89 (5), pp. 1259-1278.

Acemoglu, D. and D. Autor (2011) "Skills, tasks and technologies: Implications for employment and earnings”. In O. Ashenfelter and D. Card (Eds.), Handbook of Labor Economics, pp. 1043-1171.

Aizcorbe, A., Oliner S. D., and D.E. Sichel (2006) "Shifting Trends in Semiconductor Prices and the Pace of Technological Change.” Discussion Series, Federal Reserve Board.

Amendola, M., Vona, F., (2012) "Coordinating the Accumulation of Physical and Human Capital in different Institutional Settings”. Economic of Innovation and New Technology 21(7), pp. 631653.

Amiti, M. and D.R. Davis (2012) “Trade, Firms, and Wages: Theory and Evidence”. Review of Economic Studies 79, pp. 1-36.

Amiti, M. and C. Freund (2010) “An anatomy of China’s export growth”. In: R. Feenstra and S.J. Wei (Eds.), China’s Growing Role in World Trade. : University of Chicago Press. 
Arellano, M. and O. Bover (1995) “Another look at the instrumental variable estimation of errorcomponents models". Journal of econometrics 68(1), pp. 29-51.

Arellano, M. and S. Bond (1991) "Some Tests of Specification for Panel Data: Monte Carlo Evidence and an Application to Employment Equations”. Review of Economic Studies 58(2), pp. 277-97.

Athey, S., and S. Stern (2002) "The Impact of Information Technology on Health Care Outcomes." RAND Journal of Economics 33(3), pp. 399-432.

Autor, D. (2013) “The Task-Approach to Labor Markets: an Overview”. Journal of Labor Market Research 46(3), pp. 185-199.

Autor, D. H. and D. Dorn (2013) "The growth of low skill service jobs and the polarization of the US labor market”. American Economic Review 103(5), pp. 1553-1597.

Autor, D. H., Levy, F. and R.J. Murnane (2003) "The skill content of recent technological change: An empirical exploration”. Quarterly Journal of Economics 118 (4), pp.1279-1333.

Autor, D., Dorn, D. and G. Hanson (2013) “The China Syndrome: Local Labor Market Effects of Import Competition in the United States”. American Economic Review 103(6), pp. 2121-2168.

Autor, D., Dorn, D., Hanson, G. and J. Song (2013) “Trade Adjustment: Worker Level Evidence”. National Bureau of Economic Research.

Autor, D., Katz, L.F., and A.B. Krueger (1998) “Computing inequality: have computers changed the labor market?” The Quarterly Journal of Economics 113(4), pp. 1169-1213.

Autor, D., Katz, L.F., and M.S. Kearney (2008) "Trends in US wage inequality: Revising the revisionists”. The Review of Economics and Statistics, 90(2), pp. 300-323.

Baldwin, R. (2011) “Trade and industrialisation after globalisation’s 2nd unbundling: How building and joining a supply chain are different and why it matters”. National Bureau of Economic Research.

Basu, S. and J.G. Fernald (2007) "Information and Communications Technology as a GeneralPurpose Technology: Evidence from U.S. Industry Data.” German Economic Review 8(2), pp. 146-173.

Becker R., Gray,W. and J. Marvakov (2013) “NBER-CES Manufacturing Industry Database: Technical Notes”. (Accessed 13 September 2014).

Bernard, A.B., Jensen, J.B., and P.K. Schott (2006) "Survival of the best fit: Exposure to low-wage countries and the (uneven) growth of US manufacturing plants”. Journal of International Economics 68(1), 219-237.

Blinder, A.S. (2009) “How many US jobs might be offshorable?”. World Economics 10(2), pp. 41-78.

Blundell, R. and S. Bond (1998) "Initial conditions and moment restrictions in dynamic panel data models”. Journal of Econometrics, 87(1), pp. 115-143.

Bond, S. (2002) "Dynamic panel data models: a guide to micro data methods and practice” Portuguese Economic Journal 1, pp. 141-162.

Bond, S. and R. Blundell (2000) "GMM estimation with persistent panel data: an application to production functions”. Econometric Reviews 1, pp. 321-340.

Boschma, R., R.H. Eriksson and U. Lindgren (2014) "Labour market externalities and regional growth in Sweden. The importance of labour mobility between skill-related industries”. Regional Studies, forthcoming.

Brynjolfsson, E., and A. McAfee (2011) Race against the machine: How the digital revolution is accelerating innovation, driving productivity, and irreversibly transforming employment and the economy. Lexington, MA: Digital Frontier Press. 
Bugamelli, M., Schivardi, F. and R. Zizza (2008) “The euro and firm restructuring”. National Bureau of Economic Research.

Consoli, D., Vona, F. and T. Saarivirta (2013) “Analysis of the Graduate Labour Market in Finland: Spatial Agglomeration and Skill-Job Match”. Regional Studies 47(10), pp. 1634-1652.

Cummins, J.G., and G.L. Violante (2002) "Investment-specific technical change in the United States (1947-2000): Measurement and macroeconomic consequences”. Review of Economic Dynamics 5(2), pp. 243-284.

David, P.A. and G. Wright (2003) "General Purpose Technologies and Productivity Surges: Historical Reflections on the Future of the ICT Revolution”. In: P.A. David and M. Thomas (eds) The Economic Future in Historical Perspective, Oxford University Press for the British Academy.

Ebenstein, A., Harrison, A., McMillan, M. and S. Phillips (2013) "Estimating the impact of trade and offshoring on American workers using the current population surveys”. Review of Economics and Statistics, forthcoming.

Edwards, L. and R.Z. Lawrence (2010) "US Trade and Wages: The Misleading Implications of Conventional Trade Theory”. National Bureau of Economic Research.

Freeman, C. and C. Perez (1988) "Structural crises of adjustment, business cycles and investment behaviour”. In: Dosi, G., C. Freeman, R.R. Nelson, G. Silverberg and L. Soete (eds.) Technical Change and Economic Theory (London: Pinter), pp. 38-66.

Goldin, C. and L.F. Katz (1998) “The origins of technology-skill complementarity”. The Quarterly Journal of Economics 113(3), pp. 693-732.

Goos, M., and A. Manning (2007) "Lousy and Lovely Jobs: The Rising Polarization of Work in Britain”. Review of Economics and Statistics 89(1), pp.118-33.

Goos, M., Manning, A. and A. Salomons (2009) “The Polarization of the European Labor Market” American Economic Review Papers and Proceedings 99(2), pp. 58-63.

Gray, R. (2013) "Taking Technology to Task: The Skill Content of Technological Change in Early Twentieth Century United States”. Explorations in Economic History 50(3), pp. 351-367.

Griffith, R., S. Redding and J. van Reenen (2004) "Mapping the Two Faces of R\&D: Productivity Growth in a Panel of OECD Industries”. Review of Economics and Statistics 86, pp. 883-895.

Guadalupe, M. (2007) “Product Market Competition, Returns to Skill, and Wage Inequality”. Journal of Labor Economics 25, pp. 439-474.

Hanson, G.H. (2012) “The rise of middle kingdoms: Emerging economies in global trade”. National Bureau of Economic Research.

Hauk, W. and R. Wacziarg (2009) “A Monte Carlo study of growth regressions”. Journal of Economic Growth 14(2), pp. 103-147.

Hubbard, T.N. (2003) "Information, Decisions, and Productivity: On Board Computers and Capacity Utilization in Trucking.” American Economic Review 93(4), pp. 1328-53.

Jaimovich, N., and H.E. Siu (2012) "The trend is the cycle: Job polarization and jobless recoveries" National Bureau of Economic Research.

Jorgenson, D.W., M.S. Ho, and K.J. Stiroh (2008) "A Retrospective Look at the U.S. Productivity Growth Resurgence”. Journal of Economic Perspectives 22(1), pp. 3-24.

Katz, L.F., and Murphy, K.M. (1992) "Changes in relative wages, 1963-1987: supply and demand factors”. The Quarterly Journal of Economics, 107(1), pp. 35-78.

Krueger, A.B. (1993) "How computers have changed the wage structure: evidence from microdata, 1984-1989”. The Quarterly Journal of Economics 108(1), pp. 33-60. 
Krugman, P.R. (2008) “Trade and wages, reconsidered”. Brookings Papers on Economic Activity 1, pp. 103-154.

Krusell, P., Ohanaian, L., Rios-Rull, J.-V. and G.L. Violante (2000) “Capital skill complementarity and inequality: a macroeconomic analysis”. Econometrica 68, pp. 1029-1054.

Langlois, R. (2003) "Cognitive comparative advantage and the organization of work: Lessons from Herbert Simon's vision of the future”. Journal of Economic Psychology 24, pp. 167-187.

Levy, F., and R.J. Murnane (2004) The new division of labor: How computers are creating the next job market. Princeton University Press.

Lu, Y. and T. Ng (2013) "Import Competition and Skill Content in U.S. Manufacturing Industries". Review of Economics and Statistics 95(4), pp. 1404-1417.

Melitz, M.J. (2003) "The impact of trade on intra-industry reallocations and aggregate industry productivity”. Econometrica 71(6), pp. 1695-1725.

Nelson, R.R. and S. Phelps (1966) "Investments in Humans, Technological Diffusion and Economic Growth”. American Economic Review 56 (1/2), pp. 69-75.

Nickell, S. (1981) “Biases in dynamic models with fixed effects”. Econometrica 49(6), pp. 14171426.

Nicoletti, G. and S. Scarpetta (2003) "Regulation, productivity and growth: OECD evidence”. Economic Policy 18 (36), pp. 9-72.

Oliner, S. D. and D. E. Sichel (2000) "The Resurgence of Growth in the Late 1990s: Is Information Technology the Story?”. Journal of Economic Perspectives 14(4), pp. 3-22.

Pierce, J.R. and P.K. Schott (2012) "The surprisingly swift decline of US manufacturing employment”. National Bureau of Economic Research.

Raitano, M. and F. Vona (2013) "Competition, Firm Size and Returns to Skills: quasi-experimental evidence from Italy”. Mimeo University of Rome, La Sapienza.

Roodman, D. (2009a) “A Note on the Theme of Too Many Instruments”. Oxford Bulletin of Economics and Statistics, 71(1), pp. 135-158.

Roodman, D. (2009b) "How to do xtabond2: An introduction to difference and system GMM in Stata”. Stata Journal, 9(1), pp. 86-136.

Siegel, D. and Z. Griliches (1992) "Purchased services, outsourcing, computers, and productivity in manufacturing”. In Output measurement in the service sectors (pp. 429-460). University of Chicago Press.

Simon, H.A. (1969) The Sciences of the Artificial. Cambridge, MA.

Spitz-Oener, A. (2006) "Technical change, job tasks, and rising educational demands: Looking outside the wage structure”. Journal of Labor Economics 24(2), pp. 235-270.

Tippins, N., and M. Hilton (2010) A Database for a Changing Economy: Review of the Occupational Information Network. Panel to Review the Occupational Information Network (O-NET).

Verhoogen, E. (2008) “Trade, Quality Upgrading and Wage Inequality in the Mexican Manufacturing Sector”. The Quarterly Journal of Economics 123 (2), pp. 489-530.

Vona, F. and D. Consoli (2015) “Innovation and skill dynamics: a life - cycle approach”. Industrial and Corporate Change (Forthcoming).

Weber, D.M. and R.J. Kauffman (2011) "What drives global ICT adoption? Analysis and research directions". Electronic commerce research and applications 10(6), pp. 683-701.

Wolff, E.N. (2003) "Productivity, Computerization, and Skill Change”. National Bureau of Economic Research. 
Table 1: Summary statistics for the pooled sample

\begin{tabular}{|c|c|c|c|c|c|c|c|c|c|c|}
\hline Variable & Mean & SD & $\begin{array}{c}25 \text { th } \\
\text { percentile }\end{array}$ & $\begin{array}{c}\text { 50th } \\
\text { percentile }\end{array}$ & $\begin{array}{c}\text { 75th } \\
\text { percentile }\end{array}$ & Min & Max & N. of Obs. & Reference period & Source \\
\hline \multicolumn{11}{|l|}{ Dependent variables } \\
\hline NR intensity & 0.932 & 0.111 & 0.844 & 0.934 & 1.009 & 0.708 & 1.309 & 1008 & $1999-2010$ & O-NET \\
\hline NR intensity HS & 1.27 & 0.033 & 1.255 & 1.269 & 1.286 & 1.094 & 1.379 & 1008 & $1999-2010$ & O-NET \\
\hline NR intensity MS & 1.121 & 0.059 & 1.069 & 1.122 & 1.173 & 0.928 & 1.286 & 1008 & $1999-2010$ & O-NET \\
\hline NR intensity LS & 0.788 & 0.107 & 0.678 & 0.794 & 0.893 & 0.614 & 0.991 & 1001 & 1999-2010 & O-NET \\
\hline Wage HS & 30.936 & 4.152 & 28.155 & 30.562 & 33.342 & 16.911 & 49.93 & 1008 & $1999-2010$ & O-NET \\
\hline Wage MS & 17.645 & 2.68 & 15.85 & 17.604 & 19.31 & 10.794 & 30.64 & 1008 & $1999-2010$ & O-NET \\
\hline Wage LS & 13.856 & 2.706 & 12.092 & 13.84 & 15.262 & 8.179 & 25.289 & 1001 & $1999-2010$ & O-NET \\
\hline Value added per worker & 133.686 & 127.871 & 76.203 & 101.298 & 139.392 & 40.919 & 1850.1 & 1032 & 1998-2009 & NBER-CES \\
\hline \multicolumn{11}{|l|}{ Main variables } \\
\hline Cap Equip & 0.081 & 0.097 & 0.032 & 0.059 & 0.082 & 0.007 & 0.816 & 1032 & 1998-2009 & NBER-CES \\
\hline Imp Pen Hi-Med & 0.184 & 0.114 & 0.106 & 0.177 & 0.23 & 0.011 & 0.983 & 1007 & 1996-2007 & Schott \\
\hline Imp Pen Low & 0.063 & 0.086 & 0.01 & 0.024 & 0.098 & 0 & 0.645 & 1007 & 1996-2007 & Schott \\
\hline Imp Pen China & 0.046 & 0.057 & 0.007 & 0.02 & 0.071 & 0 & 0.601 & 1007 & 1996-2007 & Schott \\
\hline Imp Pen Low No China & 0.017 & 0.041 & 0.001 & 0.003 & 0.01 & 0 & 0.22 & 1007 & 1996-2007 & Schott \\
\hline \multicolumn{11}{|l|}{ Controls } \\
\hline Emp Sh HS & 0.2 & 0.125 & 0.119 & 0.158 & 0.203 & 0.066 & 0.743 & 922 & 1998-2009 & O-NET \\
\hline Emp Sh MS & 0.155 & 0.056 & 0.113 & 0.145 & 0.194 & 0.034 & 0.329 & 922 & 1998-2009 & O-NET \\
\hline Distance to frontier & 91.389 & 7.775 & 90.742 & 93.567 & 94.738 & 0 & 97.507 & 1032 & 1998-2009 & NBER-CES \\
\hline High Tech & 0.14 & 0.347 & 0 & 0 & 0 & 0 & 1 & 1032 & $1999-2010$ & Eurostat \\
\hline Med Tech & 0.195 & 0.396 & 0 & 0 & 0 & 0 & 1 & 1032 & $1999-2010$ & Eurostat \\
\hline Low Tech & 0.545 & 0.498 & 0 & 1 & 1 & 0 & 1 & 1032 & 1999-2010 & Eurostat \\
\hline \multicolumn{11}{|c|}{$\begin{array}{l}\text { Notes: All statistics are weighted by average employment share over the period 1999-2010. Non-routine skill intensity, wage and employment share variables have missing } \\
\text { information for the period 1999-2001 pertaining to the following industries: Other Food (3119); Apparel Accessories and Other Apparel (3159); Sawmills and Wood } \\
\text { Preservation (3211); Lime and Gypsum Product (3274); Iron and Steel Mills and Ferroalloy (3311); Cutlery and Handtool (3322); Motor Vehicle (3361); Other Furniture } \\
\text { Related Product (3379). NR intensity LS and Wage LS have additional missing values: Railroad Rolling Stock (3365) in 2003, Other Leather and Allied Product (3169) and } \\
\text { Leather and Hide Tanning and Finishing (3161) in the period 2008-2010. Information for employment share variables is missing for the year 1998. Import penetration } \\
\text { variables have missing values in the period 1996-2007for the following industries: Apparel Knitting Mills (3151); Coating, Engraving, Heat Treating, and Allied Activities } \\
\text { (3328). For year } 2007 \text { we additionally miss information for Manufacturing and Reproducing Magnetic and Optical Media (3346). }\end{array}$} \\
\hline
\end{tabular}


Table 2: Effects of Import Competition and Technology on Non-Routine Skill Intensity

Dependent Variable: NR Intensity

\begin{tabular}{|c|c|c|c|c|c|c|c|}
\hline Model & [1] & [2] & [3] & [3a] & {$[3 \mathrm{~b}]$} & {$[3 c]$} & [3d] \\
\hline \multirow[t]{2}{*}{ NR Intensity -1 } & $0.9090 * * *$ & $0.9061 * * *$ & $0.9153^{* * *}$ & $0.9495 * * *$ & $0.8894 * * *$ & $0.9059 * * *$ & $0.8960 * * *$ \\
\hline & {$[0.023]$} & {$[0.025]$} & {$[0.023]$} & {$[0.015]$} & {$[0.048]$} & {$[0.061]$} & {$[0.038]$} \\
\hline \multirow[t]{2}{*}{ Cap Equip -1 } & 0.0108 & 0.0116 & $0.0242 * *$ & $0.0058 *$ & 0.0369 & $0.0262 * * *$ & 0.0045 \\
\hline & [0.011] & [0.012] & {$[0.010]$} & [0.003] & [0.049] & {$[0.010]$} & [0.009] \\
\hline \multirow[t]{2}{*}{ Imp Pen Hi-Med -3 } & & $0.0122 *$ & -0.0068 & -0.0065 & -0.0023 & $-0.0263 * * *$ & 0.0327 \\
\hline & & {$[0.007]$} & {$[0.008]$} & {$[0.007]$} & [0.014] & {$[0.008]$} & [0.022] \\
\hline \multirow[t]{2}{*}{ Imp Pen Low -3 } & & & $0.0445^{* * *}$ & 0.0081 & $0.0442 * * *$ & $0.0590 * * *$ & 0.0499 \\
\hline & & & [0.008] & [0.049] & {$[0.010]$} & {$[0.010]$} & [0.039] \\
\hline \multirow[t]{2}{*}{ Med Tech } & -0.0032 & -0.0031 & $-0.0052 * *$ & -0.0032 & $-0.0065 * * *$ & & \\
\hline & {$[0.002]$} & {$[0.002]$} & {$[0.002]$} & {$[0.002]$} & {$[0.002]$} & & \\
\hline \multirow[t]{2}{*}{ Low Tech } & $-0.0099 * * *$ & $-0.0093 * * *$ & $-0.0108 * * *$ & $-0.0050 * *$ & $-0.0126 * * *$ & & \\
\hline & [0.003] & [0.002] & [0.002] & [0.002] & [0.003] & & \\
\hline Observations & 922 & 899 & 899 & 447 & 452 & 436 & 463 \\
\hline N. of groups & 86 & 84 & 84 & 42 & 42 & 41 & 43 \\
\hline AR2 & -0.1049 & -0.0886 & -0.1391 & -0.8143 & 0.181 & -1.1537 & 1.5728 \\
\hline AR2 crit. prob. & 0.9164 & 0.9294 & 0.8893 & 0.4155 & 0.8564 & 0.2486 & 0.1158 \\
\hline Hansen J & 69.7197 & 66.6347 & 64.7033 & 31.3199 & 34.0926 & 31.8397 & 35.6693 \\
\hline Hansen df & 63 & 63 & 63 & 28 & 28 & 27 & 28 \\
\hline Hansen crit. prob. & 0.2619 & 0.3531 & 0.417 & 0.3031 & 0.1978 & 0.2381 & 0.1512 \\
\hline Instruments & 78 & 79 & 80 & 45 & 45 & 42 & 43 \\
\hline
\end{tabular}

Notes: System GMM with Windmeijer correction for standard errors. The dependent variable is Non-Routine Skill Intensity and is an index of industry-level Non-Routine task intensity computed as: (sum of industry Non-Routine cognitive and interactive task inputs)/(sum of routine and manual task inputs). Specifications [3a] and [3b] include the sample split between industries with respectively below and above- median value of import penetration from low wage countries in the pre-sample period $1989-1995$. Specifications [3c] and [3d] include the sample split between industries with respectively below and above- median value of NR Intensity for the initial year 2002. Med Tech=Medium-Tech dummy; Low Tech=Low-Tech dummy. All regressions are weighted by average employment share over the period 1999-2010. *** Significant at the $1 \%$ level; ** Significant at the 5\% level; * Significant at the $10 \%$ level. Coefficients for the regression constant and year effects are not reported for sake of simplicity. 
Table 3: Effects of Import Competition and Technology on Non-Routine Skill Intensity in three occupational groups (High-Skill, Medium-Skill and Low-Skill)

\begin{tabular}{|c|c|c|c|c|c|c|}
\hline $\begin{array}{l}\text { Dependent Variable: NR } \\
\text { intensity }\end{array}$ & HS & MS & LS & HS & MS & LS \\
\hline Model & {$[1]$} & {$[2]$} & [3] & {$[4]$} & {$[5]$} & {$[6]$} \\
\hline \multirow[t]{2}{*}{ NR Intensity HS -1 } & $0.8164 * * *$ & & & $0.8155^{* * *}$ & & \\
\hline & {$[0.036]$} & & & [0.037] & & \\
\hline \multirow[t]{2}{*}{ NR Intensity MS -1 } & & $0.9257 * * *$ & & & $0.9195 * * *$ & \\
\hline & & {$[0.035]$} & & & {$[0.037]$} & \\
\hline \multirow[t]{2}{*}{ NR Intensity LS -1 } & & & $0.9187 * * *$ & & & $0.9179 * * *$ \\
\hline & & & {$[0.012]$} & & & [0.012] \\
\hline \multirow[t]{2}{*}{ Cap Equip -1 } & $0.0098 *$ & 0.0035 & $0.0101 * * *$ & $0.0093^{*}$ & 0.0035 & $0.0118 * * *$ \\
\hline & {$[0.005]$} & [0.004] & {$[0.004]$} & {$[0.005]$} & [0.004] & [0.003] \\
\hline \multirow[t]{2}{*}{ Imp Pen Hi-Med -3 } & 0.0012 & $0.0059 *$ & $-0.0090 * *$ & 0.0032 & $0.0078 * *$ & $-0.0241 * * *$ \\
\hline & {$[0.006]$} & {$[0.003]$} & {$[0.005]$} & {$[0.008]$} & {$[0.004]$} & [0.007] \\
\hline \multirow[t]{2}{*}{ Imp Pen Low -3 } & $0.0484 * * *$ & 0.0029 & $0.0249 * *$ & & & \\
\hline & {$[0.008]$} & {$[0.006]$} & {$[0.010]$} & & & \\
\hline \multirow[t]{2}{*}{ Imp Pen China -3 } & & & & $0.0542 * * *$ & 0.0109 & 0.0027 \\
\hline & & & & {$[0.020]$} & {$[0.014]$} & [0.013] \\
\hline \multirow[t]{2}{*}{ Imp Pen Low No China -3 } & & & & 0.0355 & -0.0138 & $0.0822 * * *$ \\
\hline & & & & {$[0.028]$} & {$[0.015]$} & [0.019] \\
\hline \multirow[t]{2}{*}{ Med Tech } & -0.0007 & -0.0001 & -0.0003 & -0.0007 & -0.0003 & -0.0006 \\
\hline & {$[0.004]$} & {$[0.001]$} & {$[0.001]$} & [0.004] & {$[0.001]$} & {$[0.001]$} \\
\hline \multirow[t]{2}{*}{ Low Tech } & -0.0031 & $-0.0011^{* *}$ & -0.0006 & -0.0027 & -0.0006 & $-0.0029 *$ \\
\hline & {$[0.003]$} & {$[0.000]$} & {$[0.001]$} & {$[0.003]$} & {$[0.001]$} & {$[0.002]$} \\
\hline Observations & 899 & 899 & 891 & 899 & 899 & 891 \\
\hline N. of groups & 84 & 84 & 84 & 84 & 84 & 84 \\
\hline AR2 & 0.2555 & 0.1217 & 1.2625 & 0.2531 & 0.1119 & 1.2311 \\
\hline AR2 crit. prob. & 0.7983 & 0.9031 & 0.2068 & 0.8002 & 0.9109 & 0.2183 \\
\hline Hansen J & 63.1799 & 67.2388 & 67.2271 & 63.2206 & 68.2538 & 65.5312 \\
\hline Hansen df & 58 & 58 & 58 & 58 & 58 & 57 \\
\hline Hansen crit. prob. & 0.2985 & 0.1902 & 0.1904 & 0.2972 & 0.168 & 0.205 \\
\hline Instruments & 75 & 75 & 75 & 76 & 76 & 75 \\
\hline
\end{tabular}

Notes: System GMM with Windmeijer correction for standard errors. The dependent variable is Non-Routine Skill Intensity and is an index of industry-level Non-Routine task intensity computed as: (sum of industry NonRoutine cognitive and interactive task inputs)/(sum of routine and manual task inputs). The dependent variable has been computed for three different groups of professions: HS=High-Skill; MS=Middle-Skill; LS=Low-Skill. Med Tech=Medium-Tech dummy; Low Tech=Low-Tech dummy. All regressions are weighted by average employment share over the period 1999-2010. *** Significant at the 1\% level; ** Significant at the 5\% level; * Significant at the $10 \%$ level. Coefficients for the regression constant and year effects are not reported for sake of simplicity. 
Table 4: Effects of Non-Routine Skill Intensity on Productivity

Dependent Variable: Change in the log of value added per worker

\begin{tabular}{|c|c|c|c|c|c|}
\hline Model & {$[1]$} & {$[2]$} & {$[2 \mathrm{a}]$} & [2b] & [3] \\
\hline \multirow[t]{2}{*}{ Distance to frontier -1} & $0.0679 *$ & $0.0770 * *$ & $0.1368^{*}$ & -0.3657 & $0.1657 * *$ \\
\hline & {$[0.035]$} & {$[0.036]$} & {$[0.068]$} & {$[0.470]$} & {$[0.078]$} \\
\hline \multirow[t]{2}{*}{ NR Intensity -1 } & $0.1861^{* * *}$ & -0.0783 & -0.2533 & $-0.5309 *$ & -0.2768 \\
\hline & {$[0.062]$} & [0.139] & {$[0.310]$} & {$[0.289]$} & {$[0.181]$} \\
\hline \multirow[t]{2}{*}{ Emp Sh HS -1 } & & $0.1460 * *$ & $0.1638 *$ & $0.3195 *$ & $0.2164 * *$ \\
\hline & & {$[0.068]$} & {$[0.094]$} & {$[0.172]$} & {$[0.088]$} \\
\hline \multirow[t]{2}{*}{ Emp Sh MS -1 } & & 0.0993* & 0.0408 & $0.1230 *$ & $0.2470 * *$ \\
\hline & & {$[0.055]$} & [0.102] & {$[0.072]$} & [0.123] \\
\hline \multirow[t]{2}{*}{ Cap Equip -1 } & & & & & $0.0122 * *$ \\
\hline & & & & & {$[0.006]$} \\
\hline \multirow[t]{2}{*}{ Imp Pen Hi-Med -2 } & & & & & -0.007 \\
\hline & & & & & {$[0.066]$} \\
\hline \multirow[t]{2}{*}{ Imp Pen Low -2 } & & & & & -0.1403 \\
\hline & & & & & [0.109] \\
\hline \multirow[t]{2}{*}{ Med Tech } & 0.0027 & 0.0054 & 0.0062 & 0.0104 & 0.0117 \\
\hline & {$[0.007]$} & [0.009] & {$[0.008]$} & {$[0.010]$} & [0.017] \\
\hline \multirow[t]{2}{*}{ Low Tech } & 0.0066 & $0.0133^{*}$ & $0.0290 * *$ & 0.0029 & $0.0232 *$ \\
\hline & [0.007] & {$[0.007]$} & {$[0.014]$} & [0.010] & {$[0.013]$} \\
\hline Observations & 836 & 836 & 418 & 418 & 815 \\
\hline N. of groups & 86 & 86 & 43 & 43 & 84 \\
\hline AR2 & 0.4831 & 0.4525 & 2.2637 & -1.2226 & 0.504 \\
\hline AR2 crit. prob. & 0.629 & 0.6509 & 0.0236 & 0.2215 & 0.6142 \\
\hline Hansen J & 39.8713 & 41.1725 & 29.7869 & 30.706 & 47.9372 \\
\hline Hansen df & 36 & 36 & 27 & 27 & 45 \\
\hline Hansen crit. prob. & 0.3019 & 0.2545 & 0.3238 & 0.2834 & 0.3545 \\
\hline Instruments & 50 & 52 & 43 & 43 & 64 \\
\hline
\end{tabular}

Notes: System GMM with Windmeijer correction for standard errors. Med Tech=Medium-Tech dummy; Low Tech=Low-Tech dummy. All covariates, except dummies, have been log-transformed. Specifications [2a] and [2b] include the sample split between industries with respectively below and above- median value of log value added in the pre-sample period 1990-1998. All regressions are weighted by average employment share over the period 1999-2010. *** Significant at the 1\% level; ** Significant at the 5\% level; * Significant at the $10 \%$ level. Coefficients for the regression constant and year effects are not reported for sake of simplicity. 
Table 5: Effects of Non-Routine Skill Intensity on Wage

Dependent Variable:

Log(Hourly Wage+1)

\begin{tabular}{|c|c|c|c|c|c|c|}
\hline Model & {$[1]$} & [2] & [3] & [4] & [5] & {$[6]$} \\
\hline \multirow[t]{2}{*}{ Emp Sh HS -1 } & 0.1455 & 0.2434 & $0.3964 * * *$ & $0.1714^{* * *}$ & $0.1221^{* *}$ & 0.002 \\
\hline & [0.187] & [0.147] & {$[0.105]$} & [0.054] & {$[0.061]$} & [0.039] \\
\hline \multirow[t]{2}{*}{ Emp Sh MS -1 } & $-0.4497 * * *$ & $-0.2149 *$ & $-0.3375 * *$ & 0.0139 & -0.0494 & -0.0457 \\
\hline & [0.101] & {$[0.116]$} & [0.137] & [0.032] & [0.047] & [0.051] \\
\hline \multirow[t]{2}{*}{ Cap Equip -1 } & 0.0301 & $0.0619 * * *$ & 0.0115 & $0.0092 * * *$ & $0.0092 * *$ & $0.0120 * * *$ \\
\hline & {$[0.021]$} & {$[0.020]$} & [0.011] & [0.003] & {$[0.005]$} & [0.004] \\
\hline \multirow[t]{2}{*}{ Imp Pen Hi-Med -3 } & -0.0375 & -0.0625 & $-0.1685^{* *}$ & $0.0518 * *$ & 0.003 & -0.0092 \\
\hline & [0.077] & [0.091] & [0.081] & {$[0.021]$} & {$[0.024]$} & [0.017] \\
\hline \multirow[t]{2}{*}{ Imp Pen Low -3 } & -0.0428 & 0.1189 & -0.0786 & 0.0224 & 0.0397 & -0.0306 \\
\hline & [0.065] & [0.113] & [0.087] & [0.018] & [0.029] & {$[0.021]$} \\
\hline \multirow[t]{2}{*}{ NR Intensity HS -1 } & $1.4716^{* * *}$ & & & $0.4562 * *$ & & \\
\hline & {$[0.360]$} & & & {$[0.205]$} & & \\
\hline \multirow[t]{2}{*}{ NR Intensity MS -1 } & & $1.2772 * * *$ & & & 0.0786 & \\
\hline & & {$[0.300]$} & & & [0.382] & \\
\hline \multirow[t]{2}{*}{ NR Intensity LS -1 } & & & $0.3094 *$ & & & -0.081 \\
\hline & & & {$[0.156]$} & & & {$[0.057]$} \\
\hline \multirow[t]{2}{*}{ Wage HS -1 } & & & & $0.7830 * * *$ & & \\
\hline & & & & {$[0.071]$} & & \\
\hline \multirow[t]{2}{*}{ Wage MS -1 } & & & & & $0.8007 * * *$ & \\
\hline & & & & & {$[0.081]$} & \\
\hline \multirow[t]{2}{*}{ Wage LS -1 } & & & & & & $0.9091 * * *$ \\
\hline & & & & & & {$[0.034]$} \\
\hline \multirow[t]{2}{*}{ Med Tech } & & & & $0.0111^{* * *}$ & -0.0066 & 0.0008 \\
\hline & & & & [0.004] & {$[0.006]$} & [0.004] \\
\hline \multirow[t]{2}{*}{ Low Tech } & & & & $0.0205^{* * *}$ & -0.0066 & -0.0085 \\
\hline & & & & [0.007] & [0.008] & {$[0.008]$} \\
\hline Observations & 899 & 899 & 891 & 899 & 899 & 891 \\
\hline N. of groups & 84 & 84 & 84 & 84 & 84 & 84 \\
\hline R-sq & 0.9412 & 0.9351 & 0.9148 & & & \\
\hline AR2 & & & & -0.6022 & 1.4027 & -0.2476 \\
\hline AR2 crit. prob. & & & & 0.547 & 0.1607 & 0.8044 \\
\hline Hansen J & & & & 59.3226 & 54.8066 & 33.0889 \\
\hline Hansen df & & & & 57 & 57 & 37 \\
\hline Hansen crit. prob. & & & & 0.3909 & 0.5578 & 0.653 \\
\hline Instruments & & & & 77 & 77 & 57 \\
\hline
\end{tabular}

Notes: Models from [1] to [3] are panel data regressions with fixed effects and robust standard errors adjusted for clustering at the industry level. Models [4]-[6] are System GMM with Windmeijer correction for standard errors. The dependent variable is log of hourly wage and has been computed for three different groups of professions: HS=High-Skill; MS=Middle-Skill; LS=Low-Skill. Med Tech=Medium-Tech dummy; Low Tech=Low-Tech dummy. All covariates, except dummies, have been log-transformed. All regressions are weighted by average employment share over the period 1999-2010.*** Significant at the 1\% level; * Significant at the $5 \%$ level; * Significant at the $10 \%$ level. Coefficients for the regression constant and year effects are not reported for sake of simplicity. 
Total employment - Manufacturing only (1999-2010)

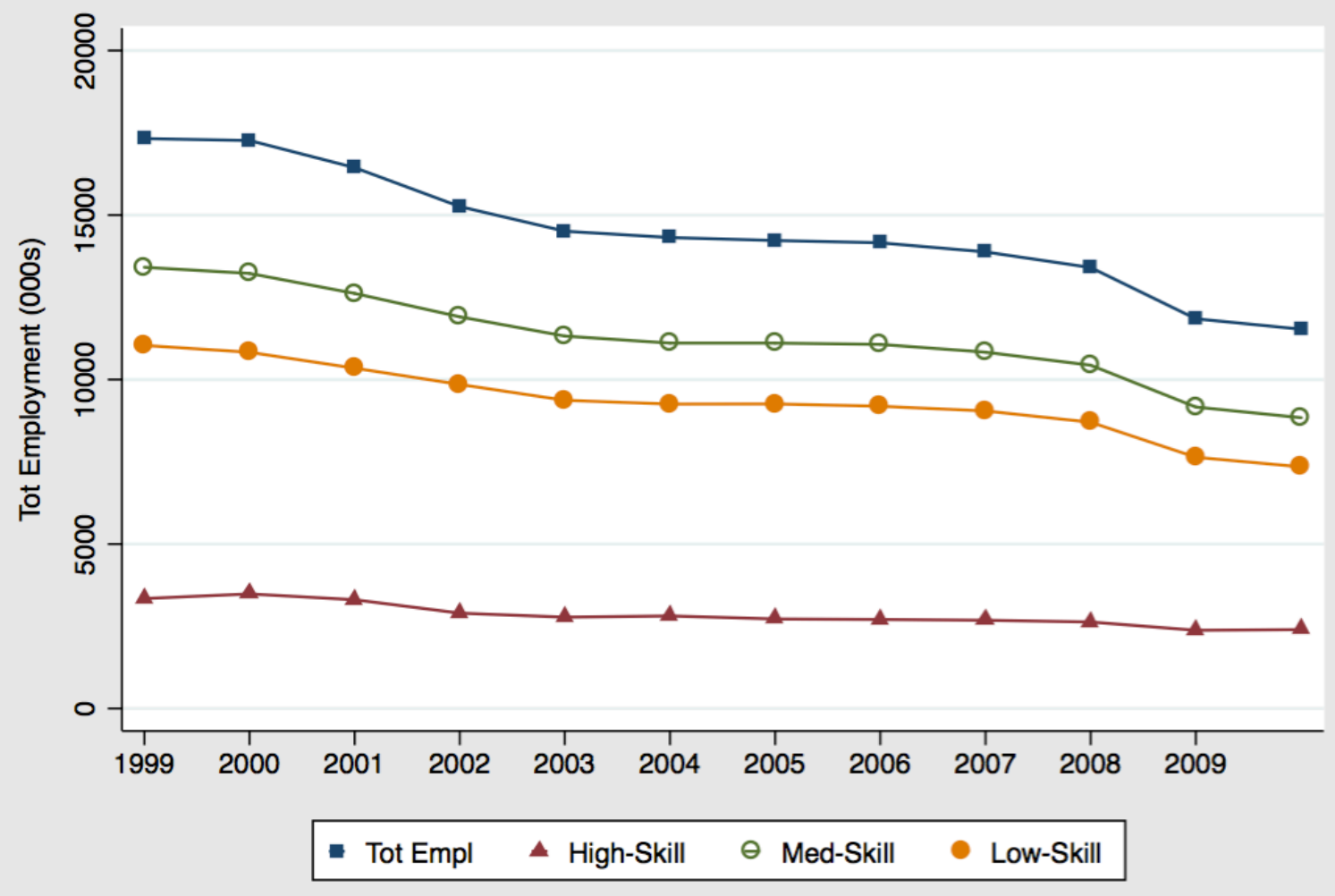

Figure 1 

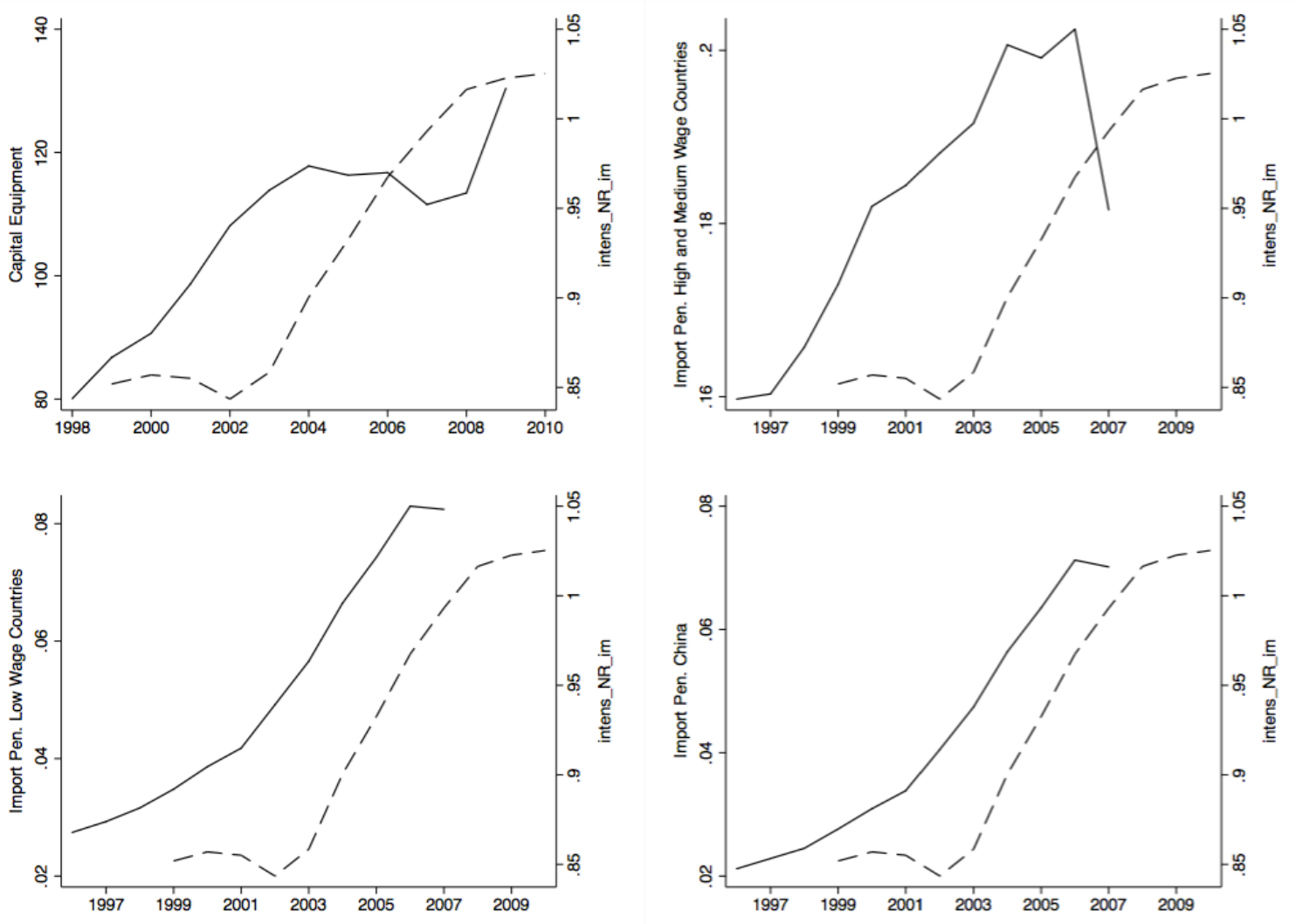

Figure 2 
Smoothed changes in NR intensity by skill percentile, 1999-2010

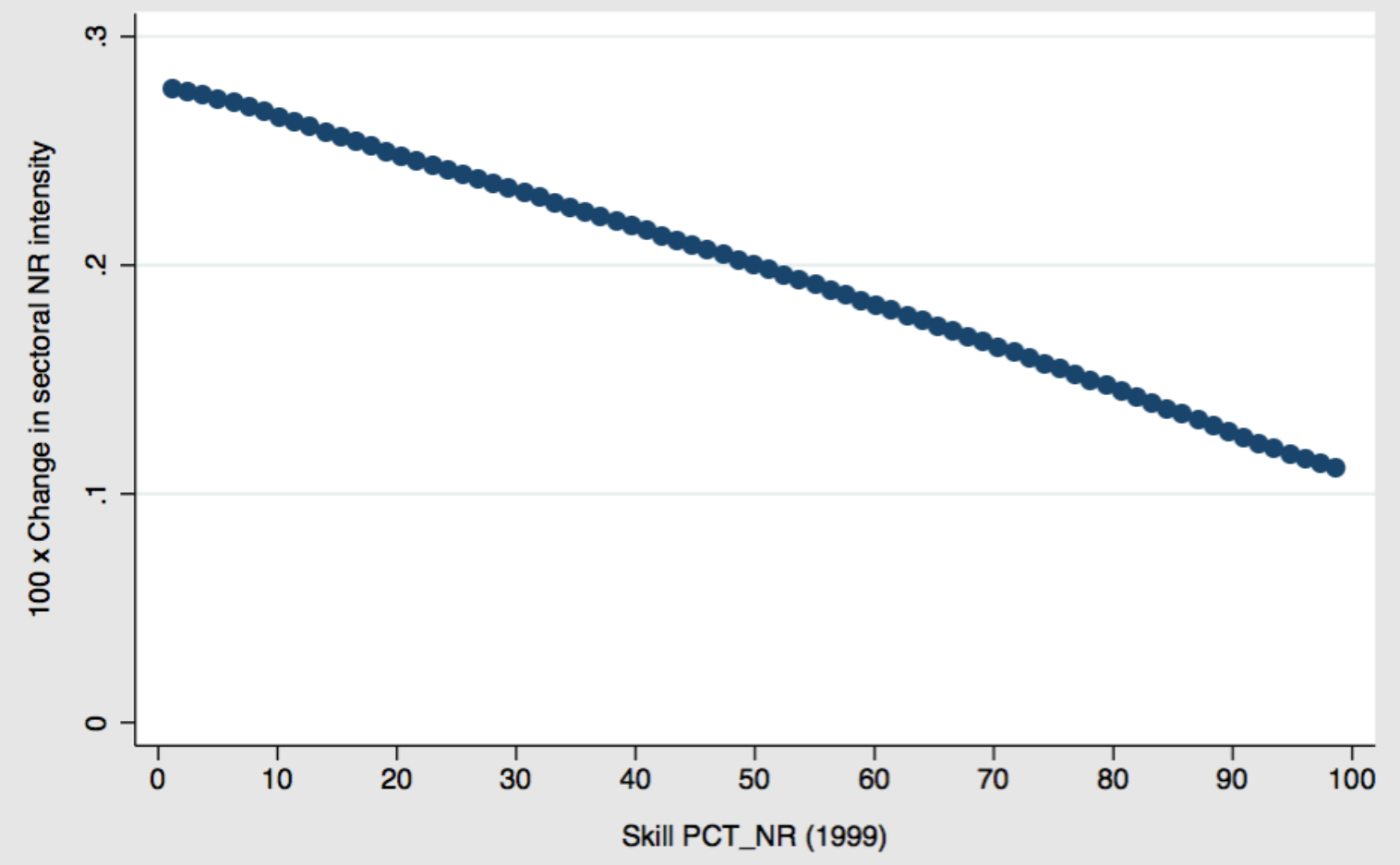

Figure 3 